\title{
Research on the Spirit of Ink Painting and Its Innovative Application
}

\author{
Wei Zhang \\ School of Fine Arts and Design \\ Nantong University \\ Nantong, China
}

\begin{abstract}
It rises an upsurge in new ink painting based on a foundation of traditional ink painting in the nowadays. We try to use the spirit of the traditional ink painting in the present popular areas, which produces innovative sparks with new ink painting. In this way, the innovative application of ink painting could not only promote the market prospect of the new ink painting in China, but also extend new vitality on the traditional ink painting spirit, thus shining new brilliance and life force.
\end{abstract}

Keywords-new ink painting; innovation of the times; application

\section{INTRODUCTION}

Chinese traditional ink painting uses water and ink as material. It don't need coloring, so it is a style of water and ink. Water and ink come from Poet Zheng Gu's Suozhi Congshi Jinfan Ouyou Huaiji. It describes: "ink painting of cool and refreshing tone makes mind awake, and rosy clouds gives Taoist robe a splendor"1. But, ink painting comes from the poem Inscription on Strange Stone near Zushanren Pond: "I heard Xiang Rong's ink painting sell at a high price in Wuzhong, so I invited him to chat under pine"2. In Chinese art history, literati and ink painting have a high status, such as, the popularity of ink painting in each family and the favor of $\mathrm{Xu}$ Qingteng, Chen Baiyang and "four monks"3. All marked the mainstream aesthetics of ancient Chinese literati.

\section{THE ORIGIN AND DEVELOPMENT OF TRADITIONAL INK PAINTING}

China ink painting, regardless of the form and artistic conception, reached to the peak to the Song Dynasty. It is a gradual evolutionary process. From the Tang Dynasty to the Yuan Dynasty, Chinese ink painting developed from "learning from the nature" to "following the inner heart", from "Confucianism" to "Taoism", from "internal" to "external", from "imperial-court decorative painting" to "literati painting". With the advent of the era of literati painting, scholars liked to take apprentices in order to hand their skills down in the Tang Dynasty. "Wu Daozi's skill was super, and he was named as "Holy Artist of Hundred Generations... at that time he took a lot of apprentices, and among them, Lu Lengqie and Yang Tingguang were excellent..." 4 Chinese ink painting was bond to transform from description of "objective object" to expression of "subjective feeling". Chinese ink painting of Yuan Dynasty was tight and powerful, with clear and original figure and silent and lasting artistic conception, which led Chinese traditional ink painting art into a sincere inner world. But no one can abandon the mastery of natural matter.

To the Ming and Qing Dynasties, Li Yu's Jiezi Garden Biography-in-Photo, Hu Zhengyan's Ten Bamboo Qihua Guide and other Chinese painting skill guides came out one after another. Then, Chinese painting subjects were sorted and simplified into a fixed "pattern". It made Chinese ink painting give up directly learning the nature. On contrary, it indirectly sought "inner heart" from ink painting dictionary. Therefore, artists can paint without the practice of sketching. Since then, traditional ink painting symbol was changed from "subjective personal creation" into "objective formulaic mode". "Without observation and sketching artists can paint. The expression of artistic conception and spirit of Chinese ink painting has become a group of brush and ink game symbols. Even it made ink painting lost life force and only with form"5.

Because of the brilliant achievements of early literati in painting, it is the key to modern painter to inherit the essence of ink painting and to current design industry to pave a new way for modern new ink painting creation. However, due to the rigid theme, superficial ink and weak conception and lack of human thinking, literati painters still put their hopes in ink painting. They forget themselves and the real world. "Ink painting sources from the humanistic spirit in the Oriental Aesthetics. Both agricultural society and industrial society have been influenced by thoughts of Confucianism, Buddhism and Taoism which are the root of social values. It contains the concept of the unity of nature and man. Even certain qualitative value system is hid between mind and understanding" 6 . The world environment has changed. Getting rid of ancient agricultural society, China, as if, has amnesia. In the process of modernization and urbanization, China has changed her value of nature. The unchangeable and remote cloud and smoke could never interpret the new nature view in the industrial society. The disability of ink painting makes scholars think of reform, so as to help it march toward modern society. The birth of new ink painting has become inevitable.

\section{THE OPPORTUNITIES OF INK PAINTING REFORM}

Art is complicated. But there are a lot of literati ink paintings, such as, Huang Gongwang's "Shengshan Painting" and Zhao Mengtiao's "Quehua Qiuse Painting" "Fig. 1". For thousands of years, water and ink are always together and share 
weal and woe. But ink painting indeed declined. Therefore, it is inevitable that the new ink painting broke out from the traditional ink and wash. Of course, from the new ink painting traces, we are not difficult to see that "the rise of the new ink painting to a great extent depends on the foundation and experience of traditional ink painting. It pupates into a butterfly. However, the literati style of traditional ink painting has too many weak points and deceitful tricks, which make painting of artists lose appeal. It wears down their broad mind in the construction of artistic conception. Though ink painting contains humanistic color and the intention of exploring the value of life, their ideal is rooted in the non-realistic illusion. In several important birthplaces of Chinese ink painting, after bypassing those exquisite furnishings and these elegant new ink paintings, there is a tired breath in the elegant culture. So, it is urgent to find a rule of right opportunity for traditional ink painting. We need to start from the innovation and transformation of traditional ink painting. Especially we can try to let other areas involved, which often can inject infinite vitality into the development of traditional Chinese ink culture and make the rigid and tired traditional ink painting with a new form of convince and appeal.

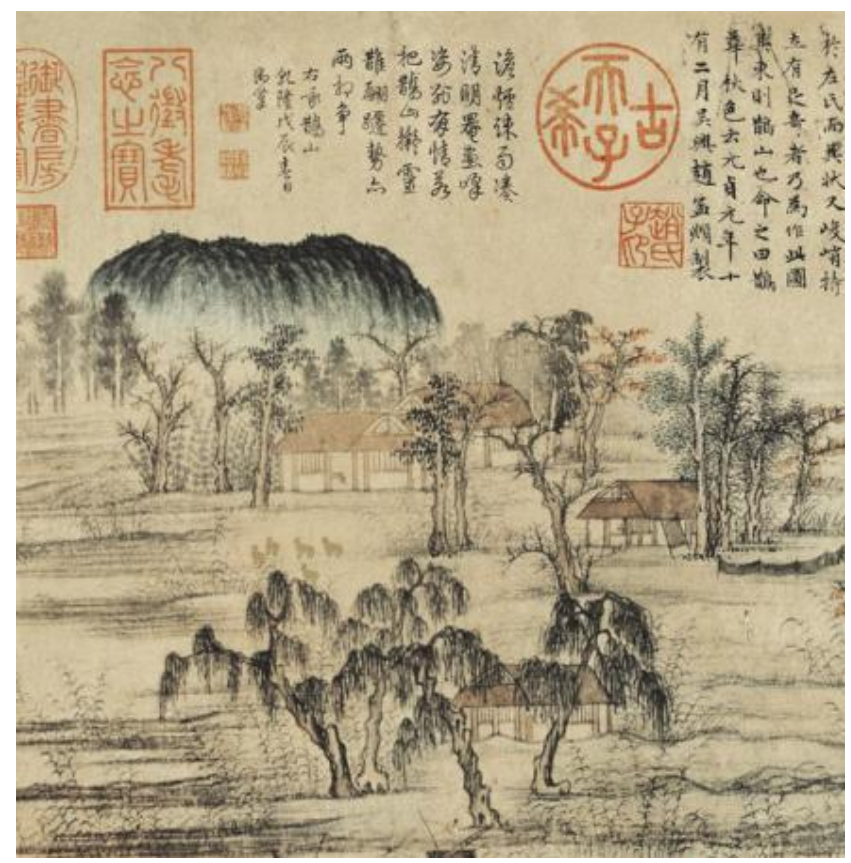

Fig. 1. Yuan Dynasty, Zhao Mengtiao's Quehua Qiuse Painting, part, collected in Taipei National Imperial Palace Museum Collection

Of course, the so-called ink painting reformers mostly only integrate skills of western and eastern paintings. They don't use sketch of modern landscape in ink painting, but use automatic skill into Chinese conception and western abstract. In fact, such innovation is a simply vassal of western painting. They are too simple to maintain "nature" and "inner heart", which makes the development of ink painting more narrow and rigid. As a pioneer of the new ink painting, despite of mastering the extremely rich knowledge and cultural awareness, he/she couldn't run out of the huge historical figure, but governs all kinds of cultural information with modern life experience. It makes Chinese new ink painting lack a vitality that is necessary in modern society.

In fact, from the end of the Twentieth Century, modern water ink painting has been against noise in traditional ink painting. The esthetic view on ink painting changed. Current new ink painting makes evolvement. Ink and wash form, ink brush order, expression force, evaluation standard, aesthetic principles and artistic aim have undergone significant changes. The traditional literati class used it to cultivate their temperament and make fun. But in modern society, it is difficult to get rid of its single and conceptual mode. The development of times makes the concept of ink painting transform. It escaped from the ink pattern, theme and evaluation standard of traditional literati on painting, and regain a new order and opportunity. At present, "new ink painting" becomes a new pronoun. There is a situation of tripartite confrontation trend among "modern ink painting", "traditional ink painting" and "new ink painting". Modern ink painting highlights its contemporary nature. It is an artistic form with realistic reference, which is rooted in the contemporary context of international integration vision, and emphasizes the present and generative nature of art.

\section{THE COMBINATION OF THE SPIRIT OF NEW INK PAINTING AND THE INNOVATION OF THE TIMES}

The rebirth of ink painting perhaps is not a hypothetical idea, but a feasible concrete measure. The development of new ink painting, in fact, is assumed and discussed for many times in other fields. We shall have the expectation of "where hills bend, streams wind and the pathway seems to end, past dark willows and flowers in bloom lies another village", and grasp the truth of "see it from different angle, it will present various looks". It is important to grasp opportunity and see the reality. The new ink painting is no longer to emphasize the artistic conception beauty of the traditional ink painting or simply reproduce the nature, but pays attention to the double innovation of spirit and concept, and closely involves the creativity of other fields in the present society. Chinese ink painting moves from the realistic art to the freehand art, from image to super image. From the perspective of Western art history, it is an evolution. The concept of base form has been known in the Song Dynasty, which is nine hundred years earlier than Cezanne. It has been embodied in the humanistic abstract concept in literati painting, earlier than Tapies' plain and simple style. $\mathrm{Mu} \mathrm{Xi}$, Zhao Mengtiao and Shi Tao have shown a freedom and calm in their paintings, which is a super understanding on art. The simple and ordinary figures in small canvas shows endless connotation. A sand, a world; a flower, a heaven. It is a direction that western art has been seeking.

Look at current environment, such as, whether the current cohesion of social consciousness is responded in real life. Use network technology to improve ink painting in order to get the favor of the public.

\section{A. The Application and Innovation of Chinese Ink Panting in Webpage Layout Design}

The compositions of webpage design layout and Chinese ink painting achieve the same result by different methods. 
Webpage designer first should design from an overall composition of webpage. Even the best ideas must be represented by visual language with changeable composition forms. The composition of ink painting is called as "presentation of idea", "overall arrangement" or "management location". In a painting, composition occupies a decisive position. It does not follow the principle of the perspective of Western painting, but has views and transform style of painters In composition, ink painting stresses "using black as blank". At the end of Southern Song, Painter $\mathrm{Mu} \mathrm{Xi}$ painted "Six Persimmons" "Fig. 2". The painting is simple and plain. But taste it carefully. It is simple but afford for thought, lonely but vivid. How to analyze the composition of the picture? How to calculate the distance between the six persimmons? Is it intentional or naïve? The painter skillfully left different "blanks" to keep the primary and secondary, size, and density. It leaves a rich imagination to others. The picture is different and unique. Therefore, the application of Chinese aesthetic art in webpage design is a good way for designer and browser to communicate.

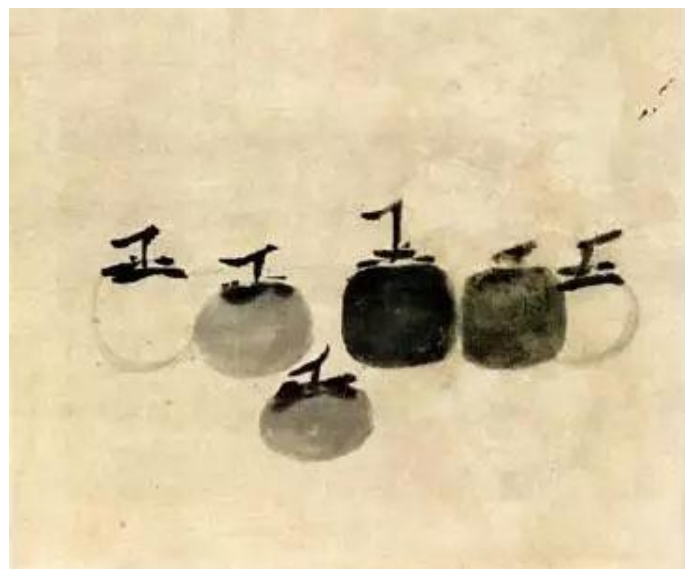

Fig. 2. Southern Song Dynasty. Mu Xi, Collected in Dade Temple in Kyoto

What's more, modern webpage design is particular about the integration of simple beauty and imaginative space. Webpage design can learn from the composition rules of traditional ink painting. Use simple overview of water and ink element to improve design conception of interface and make webpage design more diversified. The appearance of ink and water elements can enrich the visual effect of webpage. It can change the mechanical visual effect of webpage with pure word interface and create a direct vivid effect. The use of ink and brush is to present the figures in ink painting. Select different brushes to design different themes. Brush and ink are complementary to each other. The force of brush, length of line, shade and dry-wet degree of ink can reflect the different flavor and bring viewers different feelings.

The aesthetic perception is from cognition. It requires designers to grasp ink and water elements, symbol and cognition of spirit well in order to play its function. The ancient said: "measure the object and get the truth"7. Designer's aesthetic feeling on ink painting largely determines whether ink painting's quality and image can be vividly presented. Only in this way, can ink painting element be well applied in modern webpage design and reach the purpose to convey the spirit of ink painting.

\section{B. The Trans-Boundary Use of Ink Painting Spirit in Clothing Line Language}

"Art, in general, should be similar to its reflection. The wonderful point is difficult to express in words. Its idea is consistent with expression. It's solid, ingenious and wonderful..." 8 The trans-boundary use of ink painting line language in clothing is not the first time. No matter how the world changes, the classic fashion of the combination of black and white never change. In ink painting of thousands years of history, the trace and shade of ink can create deep force and life between black and white. The combination of clothing and ink painting, cotton and shade of ink and line of ink painting perfectly show the deficiency and excess of ink painting in a diversified way. Use different weaving techniques, yarn dyeing, knitting, dyeing, hand knitting and hand sewing, combine various craftsmanship and use density difference of cloth and hot fusion degree to present its changes.

Notes of Past Famous Paintings mentioned: "the shape of ink can make various colors"9. It means the use of thickness and thinness of ink can create rich changes and all kinds of layers. Clothing itself is to make different styles to different people and show their unique charm. If enlarge an ink painting and see it through the areal perspective, we will see the congealed image presented with different skills and dynamic of ink and brush. It makes plane ink line solid. It shows clothing elements through lines "Fig. 3". It makes surreal structure reasonable with details, uses pleat of different width and color and texture to express the shade of ink. It can not only reflect a majestic vigor, but also show an elegance of ink.

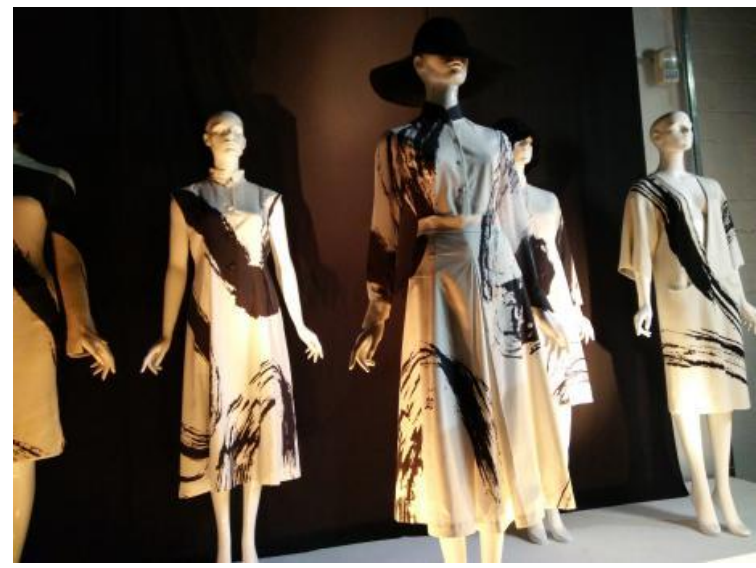

Fig. 3. Photo source: the author took in the Songshan International Exhibition in Taipei.

Of course, we can also divide ink painting into two parts: deficiency and excess. Transform the excess part webpage design. The deficiency will be the use of overall proportion. That is the line configuration rate in ink painting. Use the quality of ink painting canvas to present brush strokes and movement. Nylon is soft, but strong and thick. Reshape it to convey the concept of ink painting. So, we can use elements of ink painting in clothing, as well as rock tumbler and other. The simple and plain quality and the blank create a dynamic image. 
We can combine different materials and water and ink elements to interpret another beauty.

\section{The Application of Ink and Wash in Modern Animation}

In the 1950s and 1960s, Chinese animation (commonly known as "cartoon and puppet films") ushered in the first climax in the history of animation. As traditional animation and Chinese painting are the same strain, traditional animation reflects the characteristics of Chinese painting to varying degrees, especially in the animation of water and ink. The characteristics of ink and wash in animation tend to be "freehand brushwork" in painting which enlarges the distances between animation and film. "Ink animation deliberately ignored and evaded the realistic presentation, which is the characteristic of Chinese animation, and where film language produces contradictions. It was the demand of "freehand brushwork" that hindered the realistic scene feature of ink animation"10.

Chinese ink animation has inherited the tradition and spirit of Chinese art. It has combined modern film elements and gradually formed its own unique style. Its distinctive artistic characteristics and unique artistic style have reflected the "expressionism" of Chinese traditional animation. There are two characteristics on the whole: first, it stresses the expression of the subjective feeling. Chinese traditional culture emphasizes the use of the externalization of the inner world in creation and expresses the world through subjective feelings and experience processing. Chinese animation, regardless of using the drawing art, always reflects the expressionist tendency of the designer. For example, mountain and water painting of the Tang Dynasty, water and ink painting of the Song Dynasty, flower and bird painting of the Ming Dynasty all stressed to express author's subjective feelings through the landscape. Designer of Chinese ink animation emphasizes the expression of inner spirit, rather than the depiction of objective reality. It is an expression, not a representation.

Chinese ink animation has used the techniques of ink painting in the performance. It is totally different with foreign animation in the form. The artistic conception is also not like that of Europe or Japan, full of passion and heroism. It is a unique aesthetic of our Chinese. The new water and ink element in animation is no longer simply static works painted on the rice paper. When a dynamic element is added into intangible and beautiful ink and wash, form and conception of ink and wash has a new thought. The lively spirit and charm of Chinese ink painting refers to the vivid image full of vigor and vitality. Chinese traditional ink and wash art is not only an inheritance skill and wisdom art language, but also the voice of designers. It requires us to have a broad international perspective based on national culture and seek development and innovation on the basis of inheritance of traditional water and ink culture.

\section{CONCLUSION}

The spirit of ink painting stresses spiritual ink painting. It is not only a painting itself, but also reflections of a society, a religion, an aesthetic and a nation, a region and a modernization... Even it reflects political change, economic development and international environment and so on. For ancient Chinese, ink and water is life, culture, heaven and earth, everything. For modern people, in the face of the new century, new vision, ink painting does retain a realm. In the aesthetic form and aesthetic content, it adheres to the concept of "learning from the nature and following the inner heart", "the unity of nature and man". At the same time, it seeks new images and symbols to record the faces of the times, which cannot be ignored in the development of ink painting.

\section{REFERENCES}

[1] [Tang] Zheng Gu. Yuntai Edition II. Complete Works of Chinese Classics in Wenyuan Pavilion (1986), Page 7 8.

[2] [Song] Zhu Mu. Collection of Ancient and Modern Things, I Volume 14 Complete Works of Chinese Classics in Wenyuan Pavilion (1986), Page 31.

[3] [Yuan] Tang Hou. Appreciation on Paintings. Complete Works of Chinese Classics in Wenyuan Pavilion (1986), Page 4.

[4] Ni Zaiqin. Ink Painting - Century Discussion on Literati Aesthetics and Contemporary Ink Painting. Classic Artist Co., Ltd. Apr. 2005, Page 9.

[5] Huang Guangnan. Study of the Creation and Environmental Factors of Taiwan Ink Painting. Taipei: National Museum of History, June 1999, Page 38.

[6] [Song] Jing Hao. Mountain and Water Painting . Noting Method. Complete Works of Chinese Classics in Wenyuan Pavilion (1986), Page 1.

[7] [Song] Huang Xiufu. Famous Paintings in Yizhou. Complete Works of Chinese Classics in Wenyuan Pavilion (1986), Page 1.

[8] [Tang] Zhang Yanyuan. Notes of Past Famous Paintings, Volume II. Complete Works of Chinese Classics in Wenyuan Pavilion (1986), Page

[9] Bi Sijun. Analysis of Ink Painting Elements in Traditional Cartoon. Qufu Normal University, April 2012.

[10] Liu Siliang. New Edition of Chinese Art Thought. Taipei: Artist Press, September 2001 . 